\title{
Fontes e épocas de aplicação do nitrogênio na cultura do milho irrigado
}

\section{Sources and times of nitrogen application on irrigated corn crop}

\author{
Flávia de Andrade Meira ${ }^{1}$; Salatiér Buzetti ${ }^{2 *}$; Marcelo Andreotti ${ }^{3}$; Orivaldo Arf ${ }^{4}$; \\ Marco Eustáquio de Sá4; João Antonio da Costa Andrade ${ }^{5}$
}

\section{Resumo}

Para a obtenção de altas produtividades de milho, a nutrição mineral adequada é um dos fatores essenciais e o nitrogênio, via de regra, proporciona os maiores efeitos. $\mathrm{O}$ objetivo do trabalho foi comparar os efeitos de fontes nitrogenadas: Entec - sulfonitrato de amônio com inibidor de nitrificação, sulfato de amônio e uréia, na semeadura e/ou em cobertura, nas características agronômicas do milho conduzido em solo da região de Selvíria/MS, sob irrigação por aspersão. O trabalho foi desenvolvido na FEPE da Faculdade de Engenharia de Ilha Solteira, UNESP, Selvíria-MS, em um Latossolo Vermelho distrófico, no ano agrícola 2004/05. O delineamento experimental foi de blocos casualizados com quatro repetições, em esquema fatorial $3 \times 5$ : três fontes de $\mathrm{N}$ aplicadas na semeadura e/ou em cobertura, no estádio de 6-8 folhas, em 5 combinações $\left(0+120 ; 30+90 ; 60+60 ; 90+30\right.$ e $120+0 \mathrm{~kg}$ de $\mathrm{N}$ ha $\left.{ }^{-1}\right)$. A

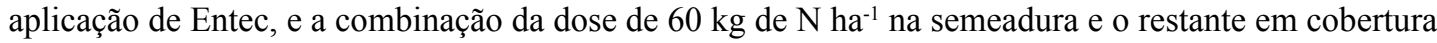
proporcionaram maior teor de $\mathrm{N}$ foliar. As maiores produtividades de grãos de milho foram conseguidas nos tratamentos que receberam as maiores doses de $\mathrm{N}$ em cobertura.

Palavras-chave: Zea mays, entec, sulfato de amônio, uréia, parcelamento de N, componentes de produção

\begin{abstract}
The mineral nutrition, mainly to concern to nitrogen, is essential to obtain high productivity in the corn crop. This work was accomplished at experimental station of State University of São Paulo UNESP - Ilha Solteira Campus, UNESP/FEIS, in Selvíria-MS, in a Red dystrophic Latosol (Oxisol), in the agricultural year 2004/05. The objective of this study was to evaluate sources and times of nitrogen application on corn yield. A randomized blocks design was used with four replications, in a $3 \times 5$ factorial scheme. The treatments were three sources of nitrogen (Entec-Ammonium sulfonitrate with nitrification inhibitor, Ammonium sulfate and Urea) applied at sowing and/or at covering, stadium of 6-8 leaves completely unfolded, in 5 combinations $(0+120 ; 30+90 ; 60+60 ; 90+30$ and $120+$ $0 \mathrm{~kg}$ of $\left.\mathrm{N} \mathrm{ha}^{-1}\right)$. The nitrogen sources as Entec and the combination of $60 \mathrm{~kg} \mathrm{ha}^{-1}$ at sowing and at 6-8 leaf stadium provided the larger $\mathrm{N}$ leaf content. The higher grain yield was reached in the treatment that received the higher $\mathrm{N}$ doses at covering.
\end{abstract}

Key words: Zea mays, entec, ammonium sulfate, urea, splitting of N, production components

1 Doutora, Pós-Graduação em Agronomia (Sistemas de Produção), Faculdade de Engenharia, Unesp, Campus de Ilha Solteira - SP.

2 Professor Titular do Departamento de Fitossanidade, Engenharia Rural e Solos, Faculdade de Engenharia, Unesp, Campus de Ilha Solteira - SP. Bolsista em produtividade pelo CNPq. E-mail: sbuzetti@agr.feis.unesp.br

3 Professor Assistente Dr. do Departamento de Fitossanidade, Engenharia Rural e Solos, Faculdade de Engenharia, Unesp, Campus de Ilha Solteira - SP.

4 Professor Titular do Departamento de Fitotecnia, Tecnologia de Alimentos e Sócio-Economia, Faculdade de Engenharia, Unesp, Campus de Ilha Solteira - SP.

5 Professor Adjunto do Departamento de Biologia e Zootecnia, Faculdade de Engenharia, Unesp, Campus de Ilha Solteira - SP.

* Autor para correspondência 


\section{Introdução}

O milho é uma das culturas de maior importância econômica e das mais estudadas devido ao valor nutricionaldeseus grãos, dadasua grandeimportância na alimentação humana, animal e matéria-prima para a indústria. O Brasil é o terceiro maior produtor deste cereal, entretanto, a produtividade média ainda é baixa, correspondendo a $3280 \mathrm{~kg} \mathrm{ha}^{-1}$ na safra 2004/05 (FNP CONSULTORIA \& COMÉRCIO, 2005), considerando que a produtividade média mundial está pouco acima de $4000 \mathrm{~kg} \mathrm{ha}^{-1}$. Entre os diversos fatores que contribuem para isto, temse destacado o manejo incorreto de fertilizantes, principalmente dos nitrogenados.

Segundo Lemaire e Gastal (1997), o nitrogênio (N)éo nutrientemineral exigidoem maior quantidade pelo milho, e é o que mais freqüentemente limita a produtividade de grãos, sendo, em geral, necessário o uso de adubação nitrogenada para complementar a quantidade fornecida pelo solo, visando obtenção de produtividades elevadas. $\mathrm{O} \mathrm{N}$, em função de suas transformações no solo, tem gerado muitas controvérsias e discussão com relação à sua época de aplicação, principalmente no milho, que é uma das culturas que apresenta maiores incrementos na produtividade em resposta à adubação nitrogenada.

Alguns resultados demonstram que a absorção de nitrogênio pelo milho é mais intensa no período entre 40 e 60 dias após a germinação, embora a planta absorva o elemento em todo o ciclo (FRANÇA et al., 1994; MACHADO et al., 1982; MAGALHÃES, 1979; VASCONCELLOS; VIANA; FERREIRA, 1998). Apesar de as exigências nutricionais serem menores nos estádios iniciais de crescimento, pesquisas indicam que altas concentrações de $\mathrm{N}$ na zona radicular são benéficas para promover o rápido crescimento inicial da planta e o aumento na produtividade de grãos (VARVEL; SCHPERS; FRANCIS, 1997; YAMADA, 1996). No estádio de quatro a seis folhas, ocorrem as diferenciações das várias partes da planta e a definição de sua produção potencial. Os componentes da produção, como número de fileiras de grãos por espiga e tamanho da espiga é definida nos estádios de quatro a seis folhas, necessitando nessa época de um suprimento adequado de N. Assim, a ocorrência de deficiência de $\mathrm{N}$ nesta fase reduz o número de óvulos nos primórdios da espiga (FANCELLI; DOURADO NETO, 2000; SCHRÕDER et al., 2000).

Com relação ao parcelamento da adubação nitrogenada, é recomendado para o Estado de São Paulo o emprego de $30 \mathrm{~kg}$ de $\mathrm{N} \mathrm{ha}^{-1}$ no momento da semeadura e o restante em cobertura (CANTARELLA; DUARTE, 1995; SÁ et al., 1995). Em função da grande mobilidade do $\mathrm{N}$ no solo, possibilitando perdas por lixiviação, é regra geral o parcelamento da adubação nitrogenada, aplicando uma pequena dose na semeadura e a quase totalidade do $\mathrm{N}$ em duas coberturas, aos 30 e 45 dias após a emergência das plantas (FORNASIERI FILHO,1992; YAMADA, 1996).

Basso e Ceretta (2000) observaram que a aplicação de $\mathrm{N}$ em uma única época (semeadura) pode resultar em acúmulo de $\mathrm{N}_{-} \mathrm{NO}_{3}^{-}$no solo nos estádios iniciais de desenvolvimento de milho, passíveis de lixiviação. Kuramoto e Fernandes (1998) concluíram que a doses de $120 \mathrm{~kg} \mathrm{ha}^{-1}$ de $\mathrm{N}$ combinada com aplicação na semeadura e cobertura influenciaram positivamente a cultura do milho.

Atualmente, no Brasil, cerca de $47 \%$ do $\mathrm{N}$ é consumido na forma de uréia, $20 \%$ como sulfato de amônio e 33\% como nitrato de amônio (POTAFOS, 2006). Portanto, as fontes nitrogenadas utilizadas com maior freqüência no milho são a uréia e o sulfato de amônio e recentemente, o Entec (Sulfonitrato de amônio $-26 \% \mathrm{~N}$ ). Este fertilizante apresenta em sua composiçãomoléculasDMPP(dimetilpirazolfosfato) que atuam na inibição da nitrificação. Isto torna o fertilizante menos susceptível à lixiviação, já que há maior tempo de permanência do N-como amônio no solo. A nitrificação vai depender da temperatura e umidade do solo (LOS FERTILIZANTES..., 2002), podendo ficar como amônio por mais de 3 meses até a metade do $\mathrm{N}$ aplicado. Dessa maneira, a eficiência 
da adubação nitrogenada pode ser ampliada, com significativa redução de perdas de $\mathrm{N}$ e maior disponibilização às plantas.

O objetivo do trabalho foi comparar os efeitos das fontes nitrogenadas, Entec, sulfato de amônio e uréia, aplicadas na semeadura e em cobertura, sobre os componentes de produção e produtividade de grãos do milho irrigado.

\section{Material e Métodos}

O estudo foi desenvolvido em lavoura irrigada por aspersão, no município de Selvíria/MS, na área da Fazenda Experimental da Faculdade de Agronomia da UNESP, Campus de Ilha Solteira. O solo foi classificado como Latossolo Vermelho Distrófico, argiloso (EMPRESA BRASILEIRA DE PESQUISA AGROPECUÁRIA - EMBRAPA, 1999), cujas características químicas na camada de 0 a $20 \mathrm{~cm}$ de profundidade foram determinadas antes da instalação do experimento, de acordo com Raij et al. (2001) e apresentavam os seguintes valores: 25 $\mathrm{mg} \mathrm{dm}{ }^{-3}$ de $\mathrm{P}_{\text {resina; }} ; 27 \mathrm{~g} \mathrm{dm}^{-3}$ de M.O., 3,2, 36, $14 \mathrm{e}$ $35 \mathrm{mmol}_{\mathrm{c}} \mathrm{dm}^{-3}$, respectivamente, de $\mathrm{K}, \mathrm{Ca}, \mathrm{Mg} \mathrm{e}$ $\mathrm{H}+\mathrm{Al}$, respectivamente, $\mathrm{pH}\left(\mathrm{CaCl}_{2}\right)$ de 5,3 e $60 \%$ de saturação por bases (V\%). Apresenta $560 \mathrm{~g} \mathrm{~kg}^{-1}$ de argila, $360 \mathrm{~g} \mathrm{~kg}^{-1}$ de areia e $80 \mathrm{~g} \mathrm{~kg}^{-1}$ de silte. Sua capacidade de campo é de $0,351 \mathrm{~m}^{3} \mathrm{~m}^{-3} \mathrm{e}$ a irrigação por aspersão foi realizada conforme leitura no Tanque classe A, sendo aplicado, em média, $12 \mathrm{~mm}$ a cada 3 ou 4 dias.

$\mathrm{O}$ experimento foi conduzido em área onde havia sido cultivado o milho no ano anterior, sendo efetuado o preparo do solo por meio de uma aração e duas gradagens. A semeadura do milho (Zea mays L.) foi realizada manualmente no dia 21 de outubro de 2004 com o híbrido triplo AGN 20A20, usandose sementes tratadas com inseticida Thiodicarb (300 $\mathrm{g} \mathrm{L}^{-1}$ ) na dosagem de $600 \mathrm{~mL}$ de i.a. por $100 \mathrm{~kg}$ de sementes. Cada parcela experimental foi constituida por 6 linhas de $5 \mathrm{~m}$ de comprimento mais $2 \mathrm{~m}$ de bordadura, sendo consideradas para as avaliações apenas as 4 linhas internas, espaçadas a $0,70 \mathrm{~m}$.
A densidade de semeadura foi planejada para se obter um estande final por volta de 60.000 plantas por hectare. $\mathrm{Na}$ adubação de semeadura foram aplicados, manualmente, no sulco, 60 e $40 \mathrm{~kg} \mathrm{ha}^{-1} \mathrm{de}$ $\mathrm{P}_{2} \mathrm{O}_{5}$ e $\mathrm{K}_{2} \mathrm{O}$, respectivamente, seguindo a tabela de recomendação de adubação para a cultura do milho irrigado, para o Estado de São Paulo, conforme Raij et al. (1997).

O controle das plantas daninhas durante o ciclo da cultura foi realizado através de aplicação em pós emergência aos 15 DAE usando atrazine $(2,5 \mathrm{~L}$ p.c./ha) + nicosulfuron (0,8 L p.c./ha) e uma capina manual aos 45 dias após a emergência. Também foi realizado o controle da lagarta do cartucho (Spodoptera frugiperda) aos 12 e aos 30 dias após a emergência, com os inseticidas Metomil (215 $\left.\mathrm{g} \mathrm{L}^{-1}\right)$ na dose de $0,2 \mathrm{~L}$ de i.a. ha ${ }^{-1}$ e Lufenuron $\left(50 \mathrm{~g} \mathrm{~L}^{-1}\right)$ na dose de 0,02 L de i.a. ha ${ }^{-1}$.

O delineamento estatístico utilizado foi o blocos casualizados, com quatro repetições, dispostos em um esquema fatorial $3 \times 5$, sendo: três fontes de nitrogênio (Entec, Sulfato de amônio e Uréia) aplicadas na semeadura e em cobertura, no estádio de 6-8 folhas completamente desdobradas, em 5 combinações $(0+120 ; 30+90 ; 60+60 ; 90+30$ e $120+0 \mathrm{~kg}$ de $\left.\mathrm{N} \mathrm{ha}^{-1}\right)$. O adubo foi posicionado na entrelinha, a uma distância de aproximadamente 20 cm do colmo das plantas de milho, sem incorporação, entretanto, irrigado logo após a aplicação.

Por ocasião do florescimento feminino, as folhas foram amostradas para diagnose foliar, determinando-se os teores de $\mathrm{N}$, de acordo com Malavolta, Vitti e Oliveira (1997). O teor de N nos grãos foi determinado mediante a coleta de uma amostra de 100 gramas de grãos em cada parcela, seguindo a mesma metodologia acima citada. A altura de inserção das espigas e o diâmetro basal médio dos colmos foram medidos por ocasião da maturidade fisiológica dos grãos, considerando a distância ente a superfície do solo e o ponto de inserção da espiga principal, e o diâmetro do segundo entrenó, respectivamente. Os componentes da 
produção avaliados foram o número de grãos/fileira da espiga, número de fileiras de grãos da espiga e massa de cem grãos. A produtividade foi obtida a partir da debulha e pesagem dos grãos oriundos de todas as espigas colhidas na área útil das parcelas experimentais em $\mathrm{kg}_{\text {parcela }}{ }^{-1}$, a qual foi convertida para $\mathrm{kg} \mathrm{ha}^{-1}$ e corrigida para $13 \%$ de umidade.

Os dados foram submetidos à análise de variância aplicando-se o teste $\mathrm{F}(\mathrm{p} \leq 0,05$ e $\mathrm{p} \leq 0,01)$, comparação de médias pelo teste de Tukey $(\mathrm{p} \leq 0,05)$, análise de correlação das avaliações individuais de componentes de planta e de produção versus a produtividade de grãos e comparação com o teste $\mathrm{t}(\mathrm{p} \leq 0,05$ e $\mathrm{p} \leq 0,01)$. Foi utilizado o programa de Análise Estatística - SANEST (ZONTA; MACHADO; SILVEIRA JÚNIOR, 1987)

\section{Resultados e Discussão}

Não foram realizadas análises estatísticas de estande final, embora não tenha havido flutuações com a aplicação de $\mathrm{N}$ totalmente na semeadura. Para os teores de enxofre foliar, todos os tratamentos apresentaram teores superiores a $3 \mathrm{~g} \mathrm{~kg}^{-1}$. A incidência de quebra de plantas não atingiu o valor mínimo pré estabelecido de 5\%, assim como a ocorrência de doenças fúngicas foi de baixa incidência.

Os quadrados médios e coeficientes de variação, assim como os valores médios referentes aos teores de $\mathrm{N}$ nas folhas, teores de $\mathrm{N}$ nos grãos, diâmetro basal dos colmos e altura de inserção das espigas encontram-se nas Tabelas 1 e 2. Verifica-se que somente para os teores de $\mathrm{N}$ foliar houve efeito significativo das fontes e das combinações de épocas de aplicação de N (Tabela 1). Possivelmente houve melhor utilização do $\mathrm{N}$ proveniente do Entec ao longo do desenvolvimento da cultura e também pela diminuição de perdas por volatilização e lixiviação. Resultados semelhantes foram relatados por Ruver et al. (2004). Para Santos e Pereira (1994), plantas com maior teor de $\mathrm{N}$ proporcionaram maior crescimento e desenvolvimento e, conseqüentemente maior índice de área foliar, conferindo maior síntese de carboidratos pela fotossíntese. Assim, a planta torna-se mais apta para alocar carboidratos para o sistema radicular, tornando-o mais abrangente e capaz de melhor aproveitar o $\mathrm{N}$ disponível, seja o $\mathrm{N}$ proveniente do solo ou do fertilizante.

Tabela 1. Quadrados médios e coeficientes de variação referentes ao teor de $\mathrm{N}$ foliar- $\mathrm{NF}\left(\mathrm{g} \mathrm{kg}^{-1}\right)$, teor de $\mathrm{N}$ grãos-NG $\left(\mathrm{g} \mathrm{kg}^{-1}\right)$, diâmetro basal do colmo-DC $(\mathrm{mm})$, e altura de inserção da espiga principal-AIEP $(\mathrm{cm})$ da cultura do milho.

\begin{tabular}{lccccc}
\hline \multicolumn{1}{c}{ FV } & G.L. & NF $\left(\mathbf{g ~ k g}^{-1}\right)$ & NG $\left.\mathbf{g ~ k g}^{-1}\right)$ & DC $(\mathbf{m m})$ & AIEP $(\mathbf{c m})$ \\
\hline Fonte (F) & 2 & $11,97^{*}$ & 0,53 & 2,01 & 1,54 \\
Época (E) & 4 & $12,45^{*}$ & 0,11 & 2,59 & 39,76 \\
Blocos & 3 & $11,88^{*}$ & 1,16 & 5,63 & 114,42 \\
F*E & 8 & 5,31 & 0,50 & 0,44 & 23,49 \\
Resíduo & 42 & 3,86 & 0,82 & 0,90 & 16,34 \\
\hline CV (\%) & & 5,99 & 5,84 & 4,50 & 3,37 \\
\hline
\end{tabular}

Obs.: * Significativo em nível de 5\% de probabilidade pelo teste $\mathrm{F}$.

Os teores de $\mathrm{N}$ nos grãos foram menores do que os encontrados por Villas Bôas et al. (1999) e Coelho et al. (1992) na faixa de 16,0 a $17,5 \mathrm{~g} \mathrm{~kg}^{-1}$, e similares aos encontrados por Godoy (2002) na faixa de 12,8 a 16,0 $\mathrm{g} \mathrm{kg}^{-1}$ (Tabela 2). Esta característica é altamente influenciada pelo genótipo e quase sempre, a adubação nitrogenada é realizada objetivando apenas aumentar a produtividade, tendo em vista, que o produtor recebe pela quantidade produzida e não pela qualidade do produto. Resultados concordantes com o deste trabalho foram obtidos por Araújo, Ferreira e Cruz (2004), os 
quais verificaram que o teor de $\mathrm{N}$ dos grãos não foi influenciado pela adubação nitrogenada. Também Silva (2001), avaliando combinações de épocas de aplicação de $\mathrm{N}$ (estádio de 6 até 10 folhas) observou que não houve diferença significativa para o teor de $\mathrm{N}$ nos grãos. Esta variável tem relação direta com o teor de proteína dos grãos e diversos trabalhos correlacionaram positivamente o teor de proteína dos grãos e a adubação nitrogenada. A quantidade de $\mathrm{N}$ a ser drenada para o grão tem relação direta como o estado nutricional das plantas e também depende do ciclo, do período de enchimento dos grãos e, principalmente, do cultivar.

Tabela 2. Médias para fontes e modos de aplicação do $\mathrm{N}$ e teste de Tukey referentes ao teor de $\mathrm{N}$ foliar- $\mathrm{NF}\left(\mathrm{g} \mathrm{kg}^{-1}\right)$, teor de $\mathrm{N}$ grãos-NG $\left(\mathrm{g} \mathrm{kg}^{-1}\right)$, diâmetro basal do colmo-DC $(\mathrm{mm})$, e altura de inserção da espiga principal-AIEP $(\mathrm{cm})$ da cultura do milho.

\begin{tabular}{|c|c|c|c|c|}
\hline FV & NF $\left(\mathrm{g} \mathrm{kg}^{-1}\right)$ & NG $\left(\mathrm{g} \mathrm{kg}^{-1}\right)$ & DC (mm) & AIEP (cm) \\
\hline & \multicolumn{4}{|c|}{ Médias para fontes } \\
\hline Sulfato de amônio & $32,59 \mathrm{ab}$ & 15,72 & 21,33 & 119,45 \\
\hline Entec & 33,63 a & 15,43 & 21,31 & 119,98 \\
\hline Uréia & $32,12 \mathrm{~b}$ & 15,50 & 20,77 & 119,57 \\
\hline \multirow[t]{2}{*}{ D.M.S. $(5 \%)$} & 1,51 & 0,70 & 0,73 & 3,11 \\
\hline & \multicolumn{4}{|c|}{ Médias para épocas de aplicação de $\mathrm{N}$} \\
\hline $0+120$ & $33,69 \mathrm{ab}$ & 15,58 & 20,70 & 120,08 \\
\hline $30+90$ & $32,72 \mathrm{ab}$ & 15,68 & 20,75 & 118,37 \\
\hline $60+60$ & 33,87 a & 15,43 & 20,97 & 122,67 \\
\hline $90+30$ & $32,10 \mathrm{ab}$ & 15,52 & 21,62 & 118,88 \\
\hline $120+0$ & $31,49 \mathrm{~b}$ & 15,48 & 21,65 & 118,33 \\
\hline D.M.S. (5\%) & 2,29 & 1,06 & 1,11 & 4,71 \\
\hline
\end{tabular}

Obs.: Médias na mesma coluna, seguidas por letras iguais, não diferem entre si em nível de significância a 5\% pelo teste de Tukey.

Quanto ao diâmetro do colmo também não foi encontrada diferença significativa para as fontes e combinações de doses de $\mathrm{N}$ (Tabelas 1 e 2). Verifica-se que as médias obtidas nos diferentes tratamentos variaram de $20-22 \mathrm{~mm}$, portanto, dentro da normalidade para o milho.

Verificou-se que não houve diferença significativa para altura de inserção da espiga (Tabelas 1 e 2). Esta também é uma característica altamente influenciada pelo genótipo e pouco dependente do meio, quando não se varia a densidade de plantas. Silva e Silva
(2002) constataram em seus experimentos que a aplicação de $\mathrm{N}$ (sulfato de amônio) na forma parcelada totalizando $120 \mathrm{~kg}$ de $\mathrm{N} \mathrm{ha}^{-1}$, aos $25 \mathrm{e}$ aos 45 dias após a semeadura, proporcionou plantas com maior altura de inserção da espiga. A aplicação de pelo menos, parte do $\mathrm{N}$ aos 25 dias após a semeadura é importante para a obtenção de maiores alturas de inserção de espiga.

Verifica-se que não houve efeito significativo dos tratamentos para todos os componentes da produção (Tabela 3). 
Tabela 3. Quadrados médios e coeficientes de variação referentes ao número de grãos por fileira- NGF, número de fileiras por espiga- NFE, massa de 100 grãos-MG (g), e produtividade de grãos-Prod ( $\left.\mathrm{kg} \mathrm{ha}^{-1}\right)$ da cultura do milho.

\begin{tabular}{lccccc}
\hline \multicolumn{1}{c}{ FV } & G.L. & NGF & NFE & MG $(\mathrm{g})$ & ${\text { Prod }\left(\mathrm{kg} \mathrm{ha}^{-1}\right)}$ \\
\hline Fonte (F) & 2 & 5,84 & 0,02 & 0,39 & 1798052 \\
Época (E) & 4 & 2,69 & 0,57 & 0,40 & $5276640^{* *}$ \\
Blocos & 3 & 3,74 & 0,23 & 0,41 & 1358641 \\
F*E & 8 & 1,33 & 0,70 & 2,11 & 1428211 \\
Resíduo & 42 & 1,81 & 0,87 & 2,25 & 1306958 \\
\hline CV $(\%)$ & & 3,59 & 6,03 & 4,50 & 15,83 \\
\hline
\end{tabular}

Obs.: ** significativo em nível de $1 \%$ de probabilidade pelo teste $\mathrm{F}$.

Avaliando a Tabela 4, verifica-se que nas médias para os tratamentos não houve diferença significativa para o número de fileiras de grãos por espiga, número de grãos por fileira e massa de 100 grãos. Esses resultados concordam com os obtidos por Silva (2001), que ao testar combinações de épocas de aplicação de nitrogênio na forma de uréia, também não verificou aumento no número de fileiras de grãos, número de grãos por fileira e massa de mil grãos de milho.

Com relação às fontes de $\mathrm{N}$ não foi encontrada diferenças para a produtividade de grãos (Tabela 4). Possivelmente a ausência de resposta das fontes deve-se ao fato de que logo após a aplicação do $\mathrm{N}$ fez-se a irrigação das parcelas, reduzindo as perdas por volatilização, principalmente da uréia. Ressaltase ainda que após a aplicação das fontes de $\mathrm{N}$ não ocorreram chuvas, evitando assim que parte do $\mathrm{N}$ aplicado fosse perdido por lixiviação. Ao irrigar a área logo após a aplicação da uréia ocorre uma redução substancial da volatilização de $\mathrm{N}-\mathrm{NH}_{3}$, em conseqüência do aumento do contato entre o fertilizante e as partículas de solo. Com isso, há um aumento da adsorção de $\mathrm{NH}_{4}^{+}$às cargas negativas do solo (SILVA et al., 1995).

Lara Cabezas, Korndorfer e Motta (1997) observaram que as perdas por volatilização de $\mathrm{NH}_{3}$ entre os vários fertilizantes, inclusive a uréia, não refletiram na produtividade do milho. Assim, as maiores produtividades de grãos foram obtidas quando o nitrogênio foi fornecido em doses maiores por ocasião da cobertura, ou seja, havia $\mathrm{N}$ disponível na solução do solo no período em que a planta requer maior quantidade. Uma explicação seria, provavelmente, devido ao fato de que o $\mathrm{N}$ aplicado na semeadura já se encontrar na solução do solo e, quando acrescido do $\mathrm{N}$ em cobertura, a planta ter maior quantidade do elemento para ser absorvido. As menores produtividades de grãos nos tratamentos em que houve fornecimento de doses maiores de $\mathrm{N}$ por ocasião da semeadura podem ser explicadas pela maior imobilização pelos microrganismos do solo, afetando a absorção de $\mathrm{N}$ pelas plantas. Quando ocorreu a liberação do $\mathrm{N}$ o estádio de maior exigência de nitrogênio para a cultura já havia passado. Também pode ter ocorrido maior lixiviação, diminuindo a concentração de $\mathrm{N}$ disponível, refletindo na menor produtividade de grãos. Já para Silva (2001), a maior produtividade de grãos foi verificada quando se aplicou metade do $\mathrm{N}$ na semeadura e metade no estádio de 4 a 6 folhas (7.296 $\mathrm{kg} \mathrm{ha}^{-1}$ ) e o menor valor quando se aplicou todo o $\mathrm{N}$ no estádio de 8 a 10 folhas. Para Godoy (2002), as plantas que receberam apenas nitrogênio na semeadura (26 kg ha-1) atingiram uma produtividade abaixo da média nacional $(2350 \mathrm{~kg}$ $\left.\mathrm{ha}^{-1}\right)$, entretanto, as plantas que receberam uma dose de $140 \mathrm{~kg} \mathrm{ha}^{-1}$ de $\mathrm{N}$ em cobertura alcançaram uma produtividade média de $9105 \mathrm{~kg} \mathrm{ha}^{-1}$.

Casagrande e Fornasieri Filho (2002) observaram que a aplicação total do $\mathrm{N}$ (uréia) na semeadura, até a dose de $90 \mathrm{~kg} \mathrm{ha}^{-1}$, não diferiu da dose aplicada, no estádio de 5-6 folhas para os componentes 
de produção (massa de mil grãos, índice de colheita, altura das plantas e espigas, número de fileiras de grãos por espiga e número de grãos) e na produtividade de grãos. Esses resultados são concordantes com os de Yamada (1995), que cita ser possível a aplicação de uma quantidade maior de $\mathrm{N}$ na semeadura, e com os de Coelho et al. (1991), que afirmaram que o fornecimento de $\mathrm{N}$ pode ser feito numa única aplicação em cobertura, para doses de até $100 \mathrm{~kg} \mathrm{ha}^{-1} \mathrm{de} \mathrm{N}$, em solos argilosos, como é o do presente trabalho.

Tabela 4. Médias para fontes e modos de aplicação do $\mathrm{N}$ e teste de Tukey referentes ao número de grãos por fileiraNGF, número de fileiras por espiga- NFE, ${ }^{(3)}$ massa de 100 grãos-MG $(\mathrm{g})$, e produtividade de grãos-Prod $\left(\mathrm{kg} \mathrm{ha}^{-1}\right)$ da cultura do milho.

\begin{tabular}{lcccc}
\hline \multicolumn{1}{c}{ FV } & NGF & NFE & MG $(\mathrm{g})$ & Prod $\left(\mathrm{kg} \mathrm{ha}^{-1}\right)$ \\
\hline & \multicolumn{4}{c}{ Médias para fontes } \\
\hline Sulfato de amônio & 37,17 & 15,40 & 33,32 & 7373 \\
Entec & 38,08 & 15,46 & 33,50 & 7416 \\
Uréia & 37,12 & 15,46 & 33,23 & 6877 \\
D.M.S. (5\%) & 1,03 & 0,71 & 1,15 & 878 \\
\hline \multicolumn{4}{c}{ Médias para épocas de aplicação de $\mathbf{~}$} \\
\hline $0+120$ & 37,25 & 15,23 & 33,20 & $7667 \mathrm{a}$ \\
$30+90$ & 37,90 & 15,60 & 33,65 & $7745 \mathrm{a}$ \\
$60+60$ & 37,48 & 15,37 & 33,38 & $7210 \mathrm{ab}$ \\
$90+30$ & 37,88 & 15,27 & 33,32 & $7388 \mathrm{ab}$ \\
$120+0$ & 36,76 & 15,73 & 33,20 & $6100 \mathrm{~b}$ \\
\hline D.M.S. (5\%) & 1,57 & 1,08 & 1,75 & 1331 \\
\hline
\end{tabular}

Obs.: Médias na mesma coluna, seguidas por letras iguais, não diferem entre si em nível de significância a 5\% pelo teste de Tukey.

Correlacionando a produtividade com as outras variáveis (Tabela 5), não foram constatados coeficientes significativos. Diferentemente dos resultados encontrados por Silva (2005) que reportou haver correlação positiva e significativa da produtividade de grãos com a altura de planta, altura de inserção da espiga, teor de $\mathrm{N}$ na folha, grãos por espiga e massa de grãos. Para Ulger, Becker e Kant (1995), o número de grãos por espiga e massa de grãos, são componentes que estão relacionados diretamente com a produtividade de grãos, o que provavelmente, estão relacionados ao maior teor de
$\mathrm{N}$ nas folhas, conduzindo a um maior enchimento de grãos. $\mathrm{O}$ fato de a concentração de $\mathrm{N}$ nas folhas se correlacionar com a produtividade de grãos é um indicativo que, para se ter um maior eficiência de utilização pela planta, o elemento deve ser aplicado em lugar, época e doses adequadas (SANTOS; PEREIRA, 1994), embora isto não tenha ocorrido no presente trabalho. Entretanto, o cultivar de milho interfere diretamente nestas correlações, uma vez que existem híbridos responsivos e eficientes em relação à outros não responsivos ou de menor eficiência na conversão do $\mathrm{N}$ aplicado. 
Tabela 5. Coeficientes de correlação simples entre a produção de grãos e ao ${ }^{(1)}$ teor de $\mathrm{N}$ foliar $\left(\mathrm{g} \mathrm{kg}^{-1}\right)$, ${ }^{(2)}$ teor de $\mathrm{N}$ grãos $\left(\mathrm{g} \mathrm{kg}^{-1}\right),{ }^{(3)}$ diâmetro basal do colmo $(\mathrm{mm}),{ }^{(4)}$ altura de inserção da espiga principal $(\mathrm{cm}),{ }^{(5)}$ número de grãos por fileira, ${ }^{(6)}$ número de fileiras por espiga e ${ }^{(7)}$ massa de 100 grãos (g) da cultura do milho.

\begin{tabular}{rrrrrrr}
\hline 1 & 2 & 3 & 4 & 5 & 6 & 7 \\
\hline $0,077^{\text {ns }}$ & $-0,110^{\text {ns }}$ & $0,064^{\text {ns }}$ & $0,051^{\text {ns }}$ & $0,210^{\text {ns }}$ & $-0,139^{\text {ns }}$ & $-0,013^{\text {ns }}$ \\
\hline
\end{tabular}

Obs.:ns. não significativo em nível de $5 \%$ de probabilidade pelo teste $\mathrm{t}$.

\section{Conclusões}

1. As maiores produtividades de grãos foram obtidas nos tratamentos que receberam as maiores doses de $\mathrm{N}$ em cobertura e no tratamento em que o $\mathrm{N}$ foi fornecido somente em cobertura.

2. A aplicação da fonte Entec com $60 \mathrm{~kg} \mathrm{ha}^{-1}$ de $\mathrm{N}$ na semeadura e o restante em cobertura proporcionou o maior teor de $\mathrm{N}$ nas folhas.

3. Os componentes de produção não foram influenciados pelas fontes e combinações de doses de N.

\section{Referências}

ARAÚJO, L. A. N.; FERREIRA, M. E.; CRUZ, M. C. P. Adubação nitrogenada na cultura do milho. Pesquisa Agropecuária Brasileira, Brasília, v. 39, n. 8, p. 771-777, 2004.

BASSO, C. J.; CERETTA, C. A. Manejo do nitrogênio no milho em sucessão a plantas de cobertura no solo, sob plantio direto. Revista Brasileira de Ciência do Solo, Campinas, v. 24, n. 4, p. 905-915, 2000.

CANTARELlA, H.; DUARTE, A. P. Adubação do milho safrinha. In: SEMINÁRIO SOBRE A CULTURA DO MILHO SAFRINHA, 3., 1995, Assis. Resumos... Campinas: IAC/CDV, 1995. p. 21-27.

CASAGRANDE, J. R. R.; FORNASIERI FILHO, D. Adubação nitrogenada na cultura do milho safrinha. Pesquisa Agropecuária Brasileira, Brasília, v. 37, n. 1, p. 33-40, 2002.

COELHO, A. M.; FRANÇA, G. E.; BAHIA FILHO, A. F. C.; GUEDES, G. A. A. Balanço de nitrogênio $\left({ }^{15} \mathrm{~N}\right)$ em um Latossolo Vermelho-Escuro, sob vegetação de cerrado, cultivado com milho. Revista Brasileira de Ciência do Solo, Campinas, v. 15, n. 2, p. 187-193, 1991.

Doses e métodos de aplicação de fertilizantes nitrogenados no cultivo do milho sob irrigação. Revista
Brasileira de Ciência do Solo, Campinas, v. 16, n. 1, p. 61-67, 1992.

EMPRESA BRASILEIRA DE PESQUISA AGROPECUÁRIA - EMBRAPA. Sistema brasileiro de classificação de solos. Rio de Janeiro: Centro Nacional de Pesquisa de Solos, 1999.

FANCELLI, A. L.; DOURADO NETTO, D. Produção de milho. Guaíba: Agropecuária, 2000.

FNP CONSULTORIA \& COMÉRCIO. Agrianual 2005: Anuário da Agricultura Brasileira. São Paulo:FNP, 2005.

LOS FERTILIZANTES y su uso. 4. ed. Roma: FAO/IFA, 2002. Disponível em: <www.fertilizer.org $>$. Acesso em: 5 set. 2006.

FORNASIERIFILHO, D. A cultura do milho. Jaboticabal: FUNEP, 1992.

FRANÇA, G. E.; COELHO, A. M.; RESENDE, M.;BAHIA FILHO, A. F. C. Parcelamento da adubação nitrogenada em cobertura na cultura do milho irrigado. In: EMPRESA BRASILEIRA DE PESQUISA AGROPECUÁRIA - EMBRAPA. Centro Nacional de Pesquisa de Milho e Sorgo. Relatório técnico anual do CentroNnacional dePesquisa de Milho e Sorgo: 19921993. Sete Lagoas, 1994. p. 28-29.

GODOY, L. J. G. Manejo do nitrogênio em cobertura na cultura do milho (Zea mays L.) em solo arenoso baseado no indice relativo de clorofila. 2002. Dissertação. (Mestrado em Agricultura) - Faculdade de Ciências Agronômicas, Universidade Estadual Paulista, Botucatu.

KURAMOTO, C. M.; FERNANDES, F. M. Resposta da cultura do milho (Zea mays L.) à adubação nitrogenada, sob semeadura direta. In: CONGRESSO DE INICIAÇÃO CIÊNTIFICA, 10., 1998. Araraquara. Resumos... Araraquara: UNESP, 1998. p. 300.

LARA CABEZAS, W. A. R.; KORNDORFER, G. H.; MOTTA, S. A. Volatilização de $\mathrm{N}^{-\mathrm{NH}_{3}}$ na cultura de milho: I- Efeito da irrigação e substituição parcial da uréia por sulfato de amônio. Revista Brasileira de Ciência do Solo, Viçosa, v. 21, n. 3, p. 481-487, 1997. 
LEMAIRE, G.; GASTAL, F. N. N uptake and distribution in plant canopies. In: LEMAIRE, G. (Ed.). Diagnosis of the nitrogen status in crops. Berlin: Springer, 1997. p. 3-43.

MACHADO, E. C.; PEREIRA, A. R.; FAHL, J. I.; ARRUDA, H. V.; SILVA, W. J.; TEIXEIRA, J. P. F. Análise quantitativa de crescimento de quatro variedades de milho em três densidades. Pesquisa Agropecuária Brasileira, Brasília, v. 17, n. 6, p. 825-833, 1982.

MAGALHÃES, A. C. N. Análise quantitativa do crescimento. In: FERRI, M. G. (Ed.). Fisiologia vegetal. São Paulo: EDUSP, 1979. v. 1, p. 331-349.

MALAVOLTA, E.; VITTI, G. C.; OLIVEIRA, S. A. Avaliação do estado nutricional das plantas: princípios e aplicações. 2. ed. Piracicaba: POTAFOS, 1997.

POTAFOS. Brasil: consumo aparente de fertilizantes. Disponível em: <www.potafos.org>. Acesso em: 8 ago. 2006.

RAIJ, B. V.; ANDRADE, J. C.; CANTARELLA, H.; GUAGIO, J. A. Análise química para avaliação da fertilidade de solos tropicais. Campinas: Instituto Agronômico, 2001.

RAIJ, B. V.; CANTARELlA, H.; GUAGGIO, J. A.; FURLANI, A. M. C. Recomendações de adubação e calagem para o Estado de São Paulo. 2. ed. Campinas: Instituto Agronômico, 1997. (Boletim Técnico, 100).

RUVER, A.; ANDREOTTI, M.; LOPES, M. C.; GUIMARÃES, V. F.; PILTZ, J. C.; IURKIV, L.; WERLE, T.; MENSCH, R. Produtividade do milho em função do modo de aplicação e fonte de adubos nitrogenados em sistema plantio direto. In: REUNIÃO BRASILEIRA DE FERTILIDADE DO SOLO E NUTRIÇÃO DE PLANTAS, 26.; REUNIÃO BRASILEIRA SOBRE MICORRIZAS, 10; SIMPÓSIO BRASILEIRO DE MICROBIOLOGIA DO SOLO, 8.; REUNIÃO BRASILEIRA DE BIOLOGIA DO SOLO, 5., 2004, Lages. Anais... Lages: SBCS, 2004. CD- ROM

SÁ, J. C. M.; VIEIRA, A. M.; BOZZA, D. L.; AHRAUS, S. FERREIRA, A. O.; BUENO, L.; SÁ, J. C. M. Nitrogênio: influencia da rotação de culturas e resposta da cultura de milho em solos sob plantio direto. In: CURSO SOBRE MANEJO DO SOLO NO SISTEMA DE PLANTIO DIRETO, 1995, Castro. Anais... Castro: Fundação ABC, 1995. p.213-227.

SANTOS, H. P.; PEREIRA, L. R. Efeito de sistemas de sucessão de cultura de inverno sobre algumas características agronômicas de milho em plantio direto. Revista Brasileira de Ciência do Solo, Viçosa, v. 29, n. 4, p. 1691-1694, 1994.

SCHRÕDER, J. J.; NEETESON, J. J.; OENEMA, O.; STRUIK, P. C. Does the crop or the soil indicate how to save nitrogen in maize production? Reviewing the state of the art. Field Crops Research, Amsterdam, v. 66, n. 2, p. 151-154, 2000.

SILVA, A. J.; LIMA JÚNIOR, M. A.; FERREIRA, N. C. M.; FRAGA, V. S. Perdas de amônia por volatilização proveniente da uréia aplicada a solos dos trópicos úmidos. Revista Brasileira de Ciência do Solo, Viçosa, v. 19, n. 1, p. 141-144, 1995.

SILVA, E. C. Manejo da adubação nitrogenada e utilização do nitrogênio $\left({ }^{15} \mathrm{~N}\right)$ da uréia, do milheto e da crotalária pelo milho sob semeadura direta em solo de cerrado. 2005. Tese. (Doutorado em Energia Nuclear na Agricultura) - Escola Superior de Agricultura "Luiz de Queiroz”, Universidade de São Paulo, Piracicaba.

. Níveis e épocas de aplicação de nitrogênio na $\overline{\text { cultura }}$ do milho em plantio direto na região de cerrado. 2001. Dissertação. (Mestrado em Sistema de Produção) Faculdade de Engenharia de Ilha Solteira, Ilha Solteira.

SILVA, P. S. L.; SILVA, P. I. B. Efeitos de épocas de aplicação de nitrogênio no rendimento de grãos do milho. Pesquisa Agropecuária Brasileira, Brasília, v. 37, n. 8, p. 1057-1064, 2002.

ULGER, A. C.; BECKER, A. C.; KANT, G. Response of various maize inbreed line and hybrids to increasing rates of nitrogen fertilizer. Journal of Agronomy and Crop Science, Berlin, v. 159, n. 3, p. 157-163, 1995.

VARVEL, G. E.; SCHPERS, J. S.; FRANCIS, D. D. Ability for in-season correction of nitrogen deficiency in corn using chlorophyll meters. Soil Science Society of America Journal, Madison, v. 61, n. 4, p. 1233-1239, 1997.

VASCONCELLOS, C. A.; VIANA, M. C. M.; FERREIRA, J. J. Acúmulo de matéria seca e de nutrientes em milho cultivado no período inverno-primavera. Pesquisa Agropecuária Brasileira, Brasília, v. 33, n. 11, p. 1835-1945, 1998.

VILLAS BÔAS, R. L; BOARETTO, A. E.; BULL, L. T.; GUERRINI, I. A. Parcelamento e largura da faixa de aplicação da uréia na recuperação do nitrogênio pela planta de milho. Scientia Agrícola, Piracicaba, v. 56, n. 4, p. 1177-1184, 1999.

YAMADA, T. Adubação nitrogenada do milho. Quanto, como e quando aplicar? Piracicaba: Potafos, p.1-5, 1996. (Informações Agronômicas, 74).

. Adubação nitrogenada do milho: como melhorar a eficiência? Piracicaba: Associação Brasileira para Pesquisa da Potassa e do Fosfato, 1995. (Informações Agronômicas, 71).

ZONTA, E. P.; MACHADO, A. A.; SILVEIRA JÚNIOR, P. Sistema de análise estatística para microcomputadores: manual de utilização. 2. ed. Pelotas: UFPel, 1987. 
